\title{
Assessing the effects of removing of energy subsidies on urban passenger transportation within the city of Tehran based on a system dynamics approach
}

\author{
Saeed Mirzamohammadi ${ }^{\mathbf{a}^{*}}$, Farid Ghaderi ${ }^{\mathrm{b}}$ and Mohammad Jadidi Ardakani ${ }^{\mathrm{c}}$
}

${ }^{a}$ School of Industrial Engineering, Iran University of Science \& Technology

${ }^{b}$ Department of Industrial Engineering, College of Engineering, University of Tehran

${ }^{c}$ School of Industrial Engineering, Iran University of Science \& Technology

ART I L E I N F O ABSTRACT

Article history:

Received March 21, 2012

Received in Revised form

April, 25, 2012

Accepted 30 May 2012

Available online

June 62012

Keywords:

Energy subsidy

Traffic volume

Public transportation

\begin{abstract}
Cheap subsidized fuel supplied to transportation section has the most impact on traffic jam and air pollution in the Iranian megacities, especially Tehran. The 5th Five-Year Development Plan of the country aims at elimination of energy subsidies. Accordingly, this study examines the effects of the increase in the price of energy carriers in two different scenarios on megacities' traffic and the corresponding variables. A system dynamics model is first designed to identify the most effective variables on traffic and urban transportation. The model considers an increase in the price of energy carriers based on the world price trends, until 2014 (the final year of the Subsidy Targeting Program), and evaluates the its impact on the relevant variables. The results reveal a short time reduction in transportation traffic volume. However, due to incremental trends in demand and production of vehicles, it returns to its first state.
\end{abstract}

(c) 2012 Growing Science Ltd. All rights reserved.

\section{Introduction}

Today, what is considered as subsidies in Iranian community is actually an indirect or direct payment as a financial assistance, economic points or granting of special excellences to private institutions, households or governmental units performed to achieve the desired goals (Ministry of Economic Affairs and Finance- Islamic Republic of Iran, 2010). According to HooriJafari and FarahmandPur (2008), the subsidy is considered as all sorts of transitive payment to support the low-income and vulnerable groups and to improve the income distribution for households or industries paid by the state treasury. Government subsidy is the different between the finished and the adjusted prices of goods or services paid by the government in support of the target group proportion to their income, the target group could have an acceptable buying power and suitable quality of life. Usually the amount of required subsidy is specified as to subtraction of the finished price of goods or services and the level of public purchasing ability (Ministry of Economic Affairs and Finance- Islamic Republic of Iran, 2010).

\footnotetext{
* Corresponding author. Tel: +98-21-77240402

E-mail addresses: mirzamohammadi@iust.ac.ir (S. Mirzamohammadi) 


\subsection{Disadvantages of non-targeted subsidies payment}

Payment of subsidies especially the price subsidies shows the government's intervention in price procedure and selection of relative equanimity for people, but in some cases, using the inappropriate methods to achieve more equanimity may results in poor efficiency and this efficiency reduction in economy can results in more injustice (Ministry of Economic Affairs and Finance- Islamic Republic of Iran, 2010). Some of the most important disadvantages of subsidies payments are as follows:

1. General payment and the reduction of subsidies payment effectiveness due to various groups of people's income,

2. Enormous increase in the consumption behavior and imposing more pressure on public resources of government budget,

3. Reducing the domestic production competitiveness in world's markets (The Secretariate of Working Group for Economic Reforms, 2008).

Among the energy consumption sections, the transportation section assigned approximately $40.3 \%$ of the total energy subsidies and achieved the highest share from these resources. From the energy carrier's point of view, gasoil has the highest amount of subsidies, about $32.2 \%$ of the total energy carrier's subsidies. Electricity and gasoline receiving $22.3 \%$ and $18.4 \%$ of the total amount of subsidies, respectively, are in the next positions. The lowest amount of subsidies is paid for liquid gas (2.5\% of total) (Power And Energy Planning Department- Ministry of Energy, 2010).

Since the problems of non-targeted subsidies, The Iranian government has implemented a plan under which subsidies for goods and services (including subsidies of energy carriers) will be gradually removed, and instead, this subsidy is paid to people based on different income groups, so that higher income groups, receive less subsidy and vice versa called "Subsidy Targeting Plan".

\subsection{Traffic and passenger transportation problem in Tehran}

Nowadays because of the increased population, urban transportation, purchasing power of vehicle users and inappropriate distribution of goods and services, traffic is considered as one of the most important problems of many big cities, including Tehran (Barabadi, 2010). One of the basics of sustainable development especially in developed countries is to reduce the people's dependency to their private vehicles as the means of urban transport and to encourage them to use public transportation such as: rail, bus, bicycle and walking. The use of private transportation vehicles (automobiles) will increase the fuel consumption and consequently increase its price, traffic, environmental pollution such as air pollution, noise pollution, and so on which is in conflict with the principles of sustainable development. General study on the public transportation system share in the cities of developed countries has shown that in cities like Rome this includes just around $40 \%$ of urban travels while the remaining $60 \%$ of travels are still performed via private transportations (Rahnama, 2008).

In Tehran, with over 8 million populations, everyday around 15 million urban travels take place. The lack of a suitable public transportation system caused a lot of problems in citizens' transportation. This inequality of supply and demand in the public transportation sector caused inappropriate systems such as passenger transportation by private vehicles to be replaced and taxi and mini-bus drivers move the passengers without paying any attention to their health and comfort (Navabakhsh \& Kaffashi, 2008).

In this article, we try to make an assessment on the effects of energy subsidies elimination on the public urban passenger transportation in Tehran. We try to find the effective variables involved in transportation and other related sections to this subject. Then finding the cause-and-effect relationships among these variables and with the use of system dynamics approach, the specified problem was modeled and finally through the implementation of the model using the appropriate software, we analyzed the subject and tried to predict its future procedure and proposed some methods to improve the weakness of the current situation. 
In the second section, a review of studies conducted in this field is presented and the important parameters used up to now were specified. In section three, we explain the modeling method of the problem using the system dynamics approach. Section 4 is dedicated to the description of applied scenarios on the model and finally section 5 shows the analysis of the results of the implementation of the model.

\section{Literature review}

In this section, some acceptable samples of urban transportation models modeled using the system dynamics approaches are presented. Sterman (2000) conducted one of the best studies in the field of urban traffic using the system dynamics approach. He described the traffic problem in US cities in the fifth chapter of his book "business dynamics" and presented it in a Causal Loop Diagram (CLD) format. We also used this model in our study to assess the problem. He began his model creation using "Pressure to Reduce Congestion" motivation. This variable, affects the "Road Construction" variable. "Road Construction" increases the "Highway Capacity" variable and leads to the reduction of "Travel Time" variable. Reduction of "Travel Time" reduces the pressure and this forms the first negative feedback in the problem.

He gradually extended his model and finally concluded that making the roads will increase the amount of traffic in long term because it attracts the population to that area. Another prediction of this model is that gradually the usage of public transportation will be eliminated because "Road Construction" decreases the "Travel Time" and this increases "Attractiveness of Driving" and as a result, the use of the public transportation system will be decreased. The costs will not be reduced much because most of them are fixed costs of providing services. For example, buses must travel in city even if they were empty. If the supervisors try to compensate the lack of required budget by cutting the prices, the quality of service will be decreased, travel paths will be closed and the frequency of services will be disconnected. The attractiveness of driving will be increased and "Public Transit Ridership" will be decreased gradually. The "Public Transit Deficit" will become greater and gradually shows its impact on "Public Transit Network" and its "Adequacy" to passengers will be decreased. Finally, Sterman proposed some approaches to resolve these problems (2000).

Trinh (2003) explained that economic development and urbanity imposed different challenges to the transportation system and proposed a system dynamics method to study the impact of existing urban transport situation of Hanoi. In this paper, all the cause and effect variables of congestion are investigated and analyzed using the proposed method. The indicators and long term policies are proposed based on this method and evaluated. This study tried to find another method to have a more integrated vision of different effective factors on the urban traffic issues.

Chen et al. (2009) predicted the environmental effects of urban transportation planning in China using the SD method. They described that the SD method is usually used to solve complex non-linear issues and investigated the environmental effects associated with urban transportation planning in the city of Jilin in China in respect to their domestic economy, society, transportation, environment and resources. To achieve this, they produced some simulation models including dependant subsystems to create changes in economy, society, making of roads, changes in the number of transportation vehicles, road network capacity, rate of nitrogen oxide emission, traffic noise, land used for road making and fuel consumption related to traffic. Then two simulation scenarios were analyzed. The model used in this study was designed to include the effects of these subsystems including economy, society, transportation, resources and environment. In addition, each subsystem is produced so that it could analogize the dynamic nature of the whole system and the interrelations between these subsystems. 
The results of this study demonstrated that the implementation of the transportation planning in Jilin, can improve the existing urban traffic and help the economy, the development of the area and its environment.

\section{Modeling the traffic and passenger transportation problem in Tehran}

In order to model and simulate the traffic problem in Tehran, the system dynamics approach has been used. The system dynamics is a method which uses the computer to analyze and design systems. Forrester first introduced this method in 1961 as the "industrial dynamics".

He defined his method as: "... the study of the information feedback characteristics of industrial activity to show how organizational structure, amplification (in policies), and time delays (in decision and actions) interact to influence the success of the enterprise. It treats the interactions between the flows of information, money, orders, materials, personnel, and capital equipment in a company, an industry, or a national economy". Considering the information feedback and delays in the systems, this method helps us understand the dynamic behavior of complex systems (Angerhofer \& Angelides, 2000).

In this article, we assume that traffic is only caused by the movements of personal automobiles. To start the modeling, we need an intermediate variable to relate the fuel price issue to the traffic issue. This variable is called "Driving Attractiveness" which encourages the people to use their personal automobiles for urban travels. Attractiveness affects the number and the length of travels and finally changes the amount of "Traffic Volume" (Fig. 1).

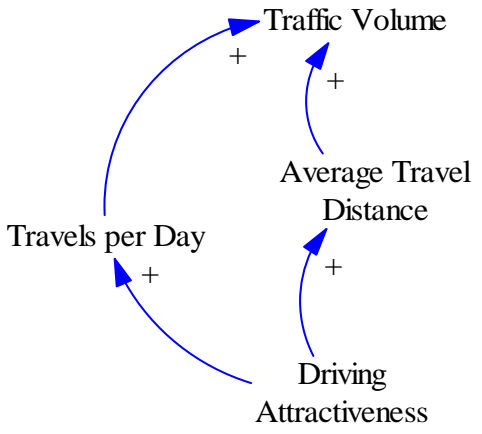

Fig. 1. Effect of "Driving Attractiveness" on "Traffic Volume"

Positive signs on the arrows show the direct relationship between the variables on both sides of the arrow. But "Traffic Volume" also has another factor and it is the number of automobiles. By increasing the number of automobiles, the traffic volume also increases. This consequently increases the "travel time" and moves it to an undesirable situation. This will also decreases "Driving Attractiveness". In Fig. 2, the B1 and B2 feedbacks prevent the traffic overflow.

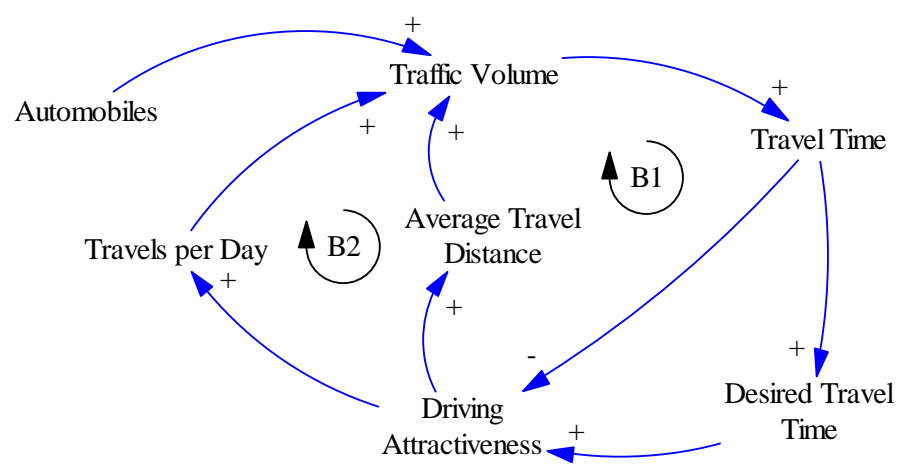

Fig. 2. First feedbacks of the model 
We should mention that "Desired Travel Time" depends on the "Travel Time" because the appropriateness of travel time, changes in different periods of time and places. For example, "Desired Travel Time" for the people in a city with high "Travel Time" rate is larger than "Desired Travel Time" for the people in a city with low "Travel Time" rate.

However, increasing the difference between "Travel Time" and "Desired Travel Time" has another impact too and that is the increase in social pressure on government to lower the traffic volume. This pressure, made the government to act and to increase the "Public Transportation Capacity" so that passengers can travel faster and easier in the city. This again affects "Driving Attractiveness" in reverse and therefore produces the B3 cycle. Fig. 3 shows the Causal Loop Diagram (CLD) of these changes.

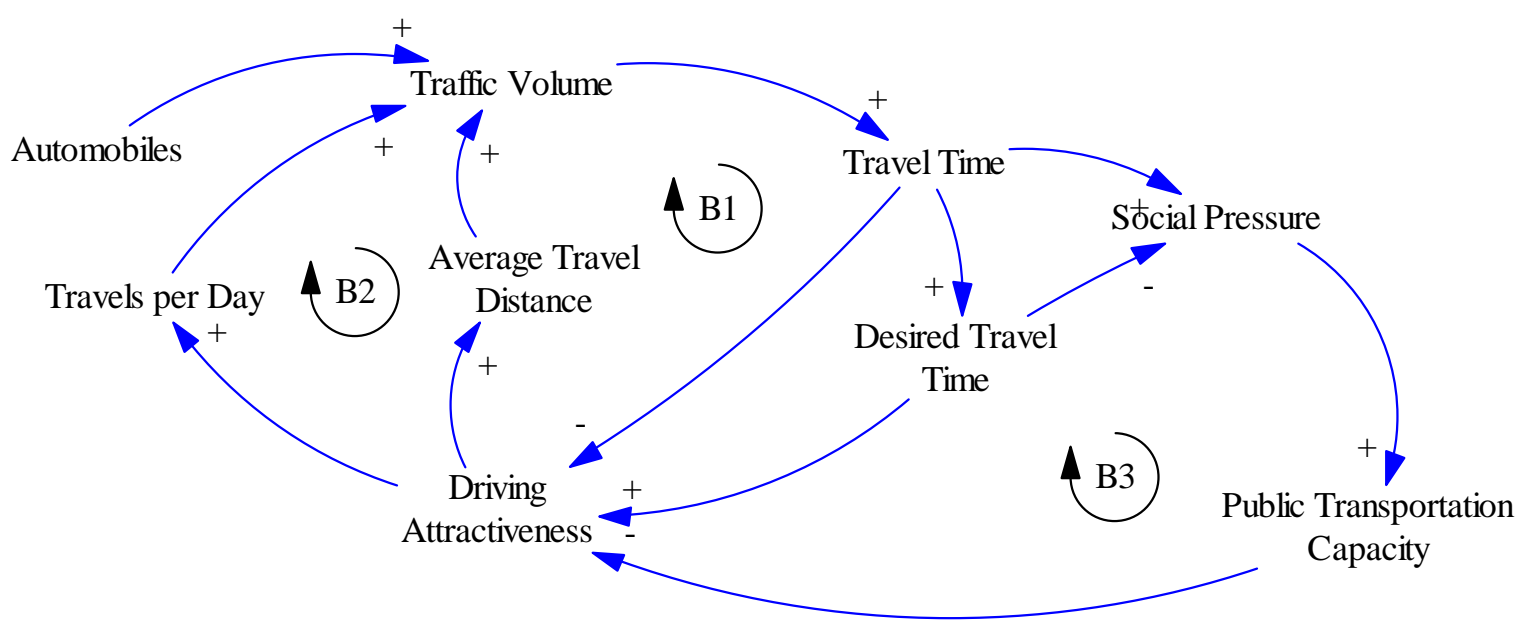

Fig. 3. Government reaction towards decreasing the traffic

However, how the increase in the price of the energy carriers affects the traffic volume? In this model, the price of carriers is shown as "Fuel Price". "Fuel Price" changes the driving costs in three ways: "Fuel Cost", "Repair Cost" and "Insurance Cost". "Driving Cost" has a feedback from "Average Travel Distance" in such a way that by increasing the travel distance, "Driving Cost" will be increased too. This feedback loop is called B4 as shown in the corresponding figure.

In addition "Fuel Price" increases "Cost of Using Public Transportation" by increasing the ticket prices and travel fees. However, compared with "Driving Cost" this increasing is much smaller because it is controlled and administered by government. For the people, the driving costs are inappropriate and lowers "Driving Attractiveness". This fact is reversely true about "Cost of Using Public Transportation". It should be mentioned that "Driving Attractiveness" in here means its attractiveness compared with the public transportation and therefore any increase in the public transportation fees will decrease the attractiveness of its usage and therefore increases "Driving Attractiveness". In addition, "Fuel Price" is an exogenous variable, which is used for policy setting in this paper. In the causal diagram of fig. 4, the new changes were applied. In addition, for simplicity, "Average Travel Distance" variable is shown as a shadow variable inside the $<>$ marks.

There are two other variables related with "Driving Attractiveness". One of them affects it and the other is affected by it. The first variable is "Society Welfare". The higher this variable will be, the people will be less sensitive about the driving and public transportation costs and this means the increase of attractiveness because of the increase in "Society Welfare". 


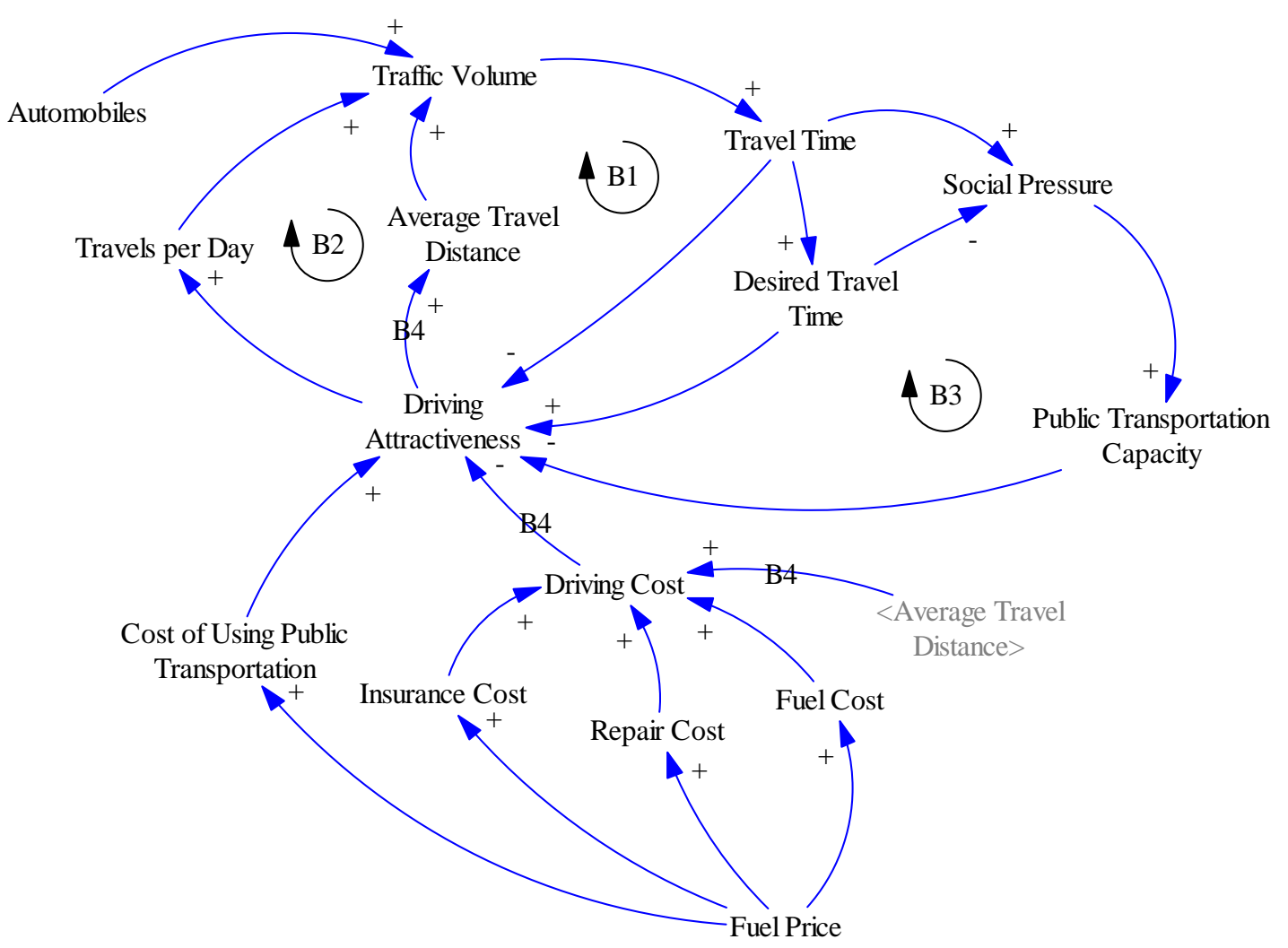

Fig. 4. Adding "Fuel Price" to the model

However, the other variable affected by "Driving Attractiveness" is the number of travels conducted by public transportation. It is obvious that when driving has enough attractiveness for the people in a city, they prefer less to travel by public transportation. This variable accompanied with "Cost of Using Public Transportation" variable, provides the governmental profit. The amount of this profit is used to increase the capacity of public transportation (Fig. 5). This provides the first positive feedback for our issue as R1.

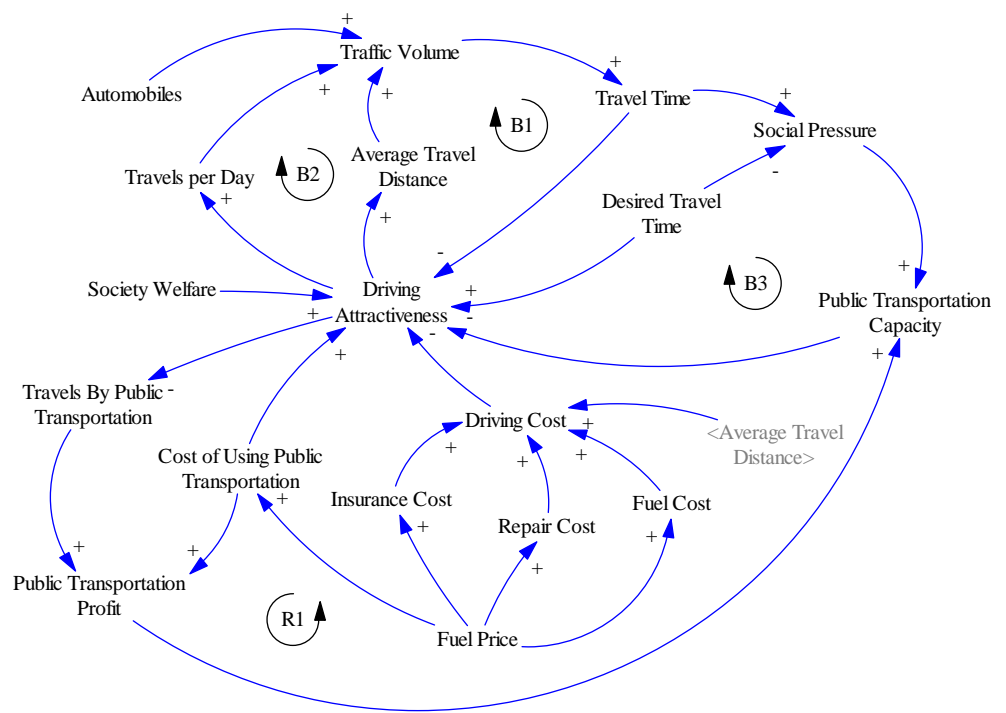

Fig. 5. Relations of "Society Welfare" and "Travels By Public Transportation" with "Driving Attractiveness" 
Yet the role of the population of Tehran has not been considered in the traffic and transportation issue of this city. This variable is related with the developed model in two ways. The first way is through path of the number of travels taken place by public transportation. The second way is through the path of the amount of demand for personal vehicles which causes more vehicle production (or import) and finally increasing the number of vehicles in the city. This demand and vehicle production is about the vehicles within the city but there are a lot of vehicles moving through the city every day from nearby towns or other cities. We consider these vehicles as the "Suburban Automobiles" in our model.

The relationship between the "Population" and the last part has been shown as two paths in Fig. 6. As shown, the "Population" first produces "Total Urban Travels" using the "Travel Rate" variable and based on that, the amount of travels by means of public transportation can be calculated. The "Travel Rate" variable shows the average number of travels done by each person in each unit of time.

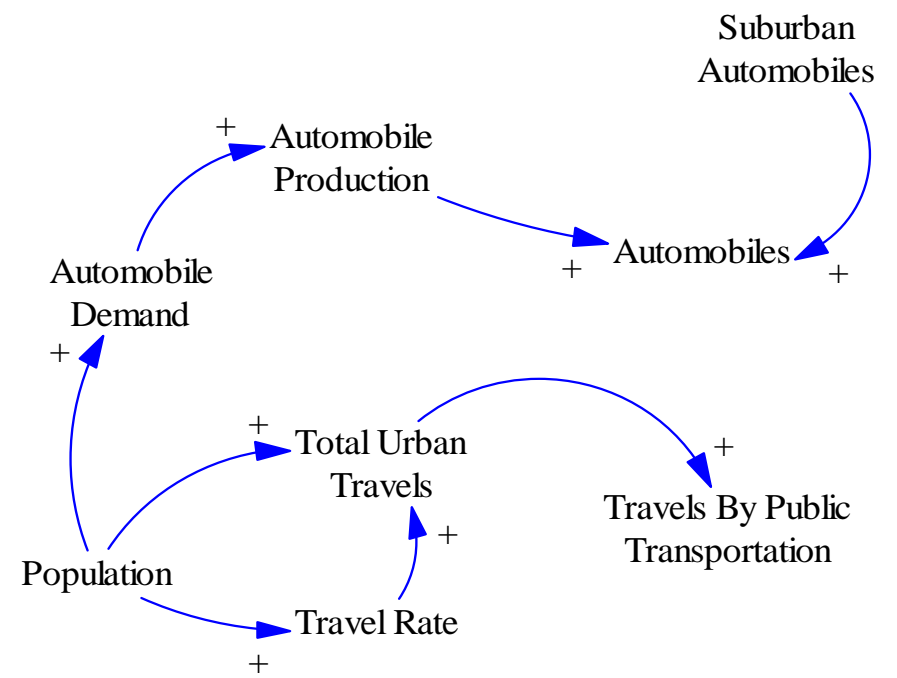

Fig. 6. Effect of "Population" on the model in two ways

Of course, not only the population do they increase the vehicle demand rate but also the society welfare level has an important effect to encourage the people to buy personal vehicles. In addition, the society welfare level can affect the "Population" variable. If there was a high welfare level in a city, gradually people from other cities were attracted to that city and vice versa. Other variables influencing the "Population" as feedbacks are "Birth Rate" and "Death Rate" (Fig. 7).

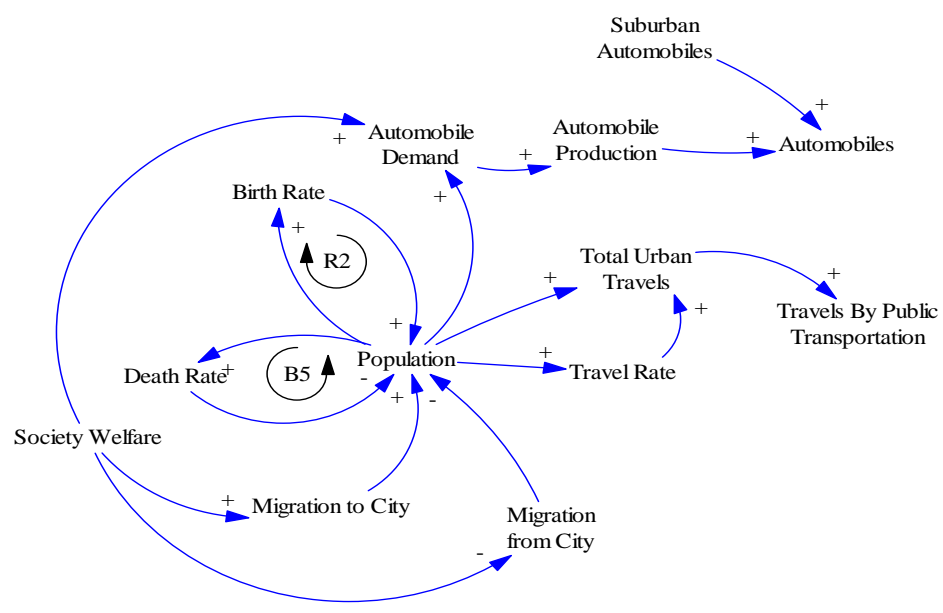

Fig. 7. Effect of "Society Welfare" on "Population" and "Automobile Demand" 
By developing the causal diagram, the flow diagram of the issue can be created as shown in Fig. 8 . The two variables, "Public Transportation Capacity" and "Population" are considered as the state variables and their corresponding rate variables are brought with them.

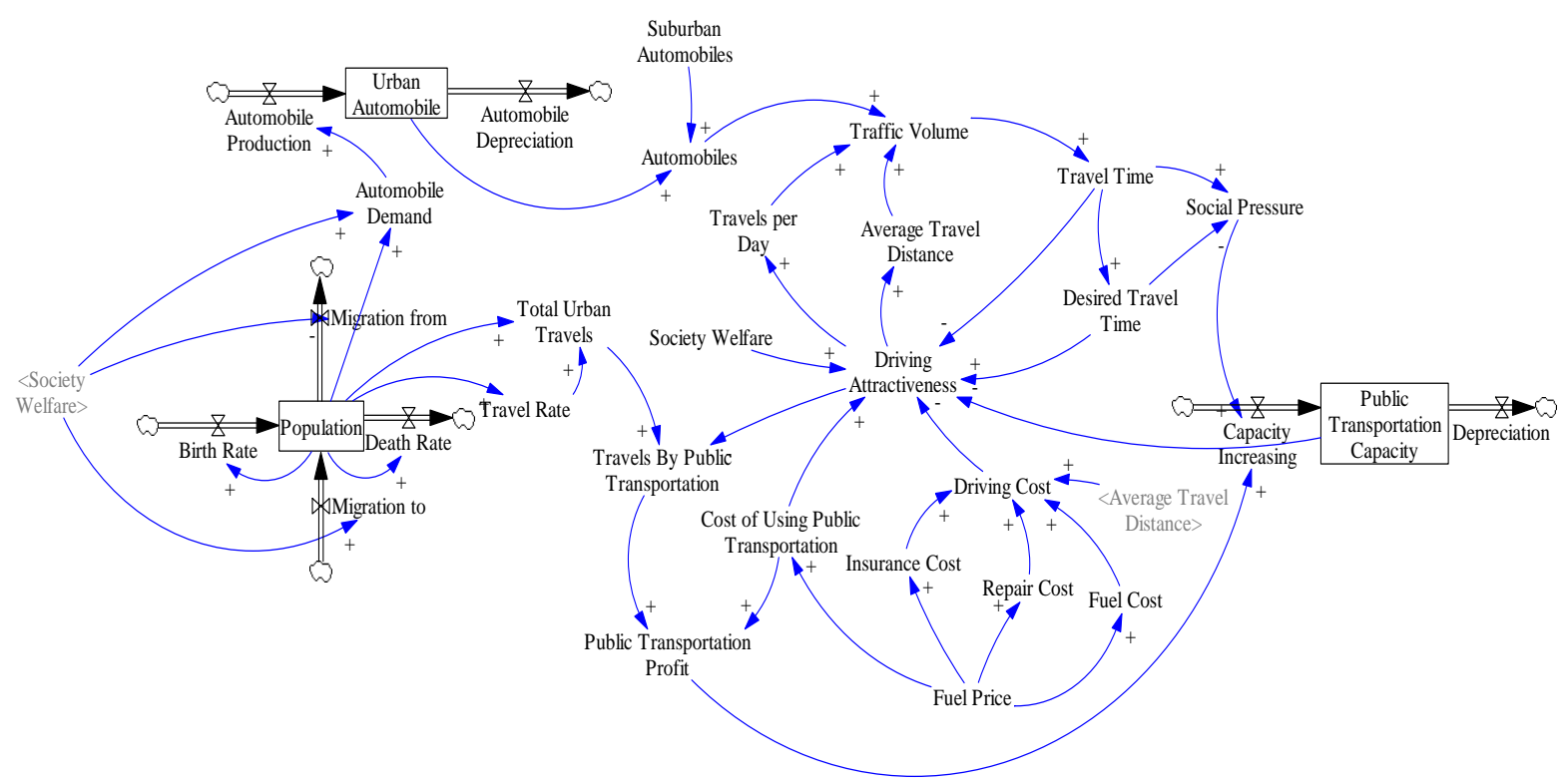

Fig. 8. Stock and flow diagram of the final model

\section{The executed scenarios}

Except for the electricity price, the price of the other three energy carriers, natural gas, gasoil and gasoline, which affect the transportation costs more than others, is not determined for the last year of the Subsidy Targeting Plan (2014) and should be predicted. This has been done in a paper named "Calculating the final price of electricity production because of the increase in electricity price and other energy carriers during the execution of the subsidies plan" by Salimian et al. They predicted the price of oil products (gasoline and gasoil) and natural gas price based on the oil price changes in 2014. For example they used proportion of the natural gas price to petroleum in two markets, Henry Hub (for natural gas) and WTI (for petroleum) between the years 2003 and 2009 and also by considering the predicted petroleum price in the Outlook energy report provided by EIA in 2009 to predict the natural gas price in 2014 (Salimian et al., 2010).

Now considering the calculated prices in 2014 in the mentioned study, we increase the carriers' prices each year until the final rate in 2014 based on the two proposed scenarios and assess the model results. Two scenarios about the elimination of subsidies have been implemented on the model:

I. Increasing the carriers' prices with a constant rate until 2014.

II. A $60 \%$ sudden increase in the carriers' prices in the first year and then increasing it with a constant rate until 2014. These scenarios are compared with the situation in which the carriers' prices increase based on the increasing rate before the subsidies plan execution. This increasing rate was calculated using the regression method.

The prices of electricity, natural gas, gasoil and gasoline on the base year (2009) were 165, 104.5, 165 and 1000 rials (Iran currency) and in the last year (2014) these prices would be 1000, 4034.2, 7353.5 and 7353.5 rials, respectively.

We used the Vensim simulation software to run the proposed model. The length of the simulation run was 9 years from 2006 to 2015. The simulation time period began from 2006 so that we can compare the model results with the historical data in the behavior reproduction validation test. In addition, we 
considered the year 2015 (one year after the end of the subsidies elimination plan) in our simulation so that we can find the last results obtained from the plan execution.

\section{Discussion and conclusion}

In this section, the changes in two important variables in the transportation issue were shown (Fig. 9 \& Fig. 10), which are the "Traffic Volume" and the "Travels By Public Transportation". The simulation results show that the amount of "Traffic Volume" is suddenly reduced after the subsidies elimination but again this indicator will be gradually increased and during several years, we will have almost the same amount of traffic. This is true in both scenarios. The difference is that in the second scenario, the amount of initial shock to the traffic is greater and the "Traffic Volume" is lower than the first scenario almost until the end of the plan (Subsidy Targeting Plan). However, during the next years, increasing the prices has no considerable effects on the "Traffic Volume" and its incremental trend will continue (Fig. 9).

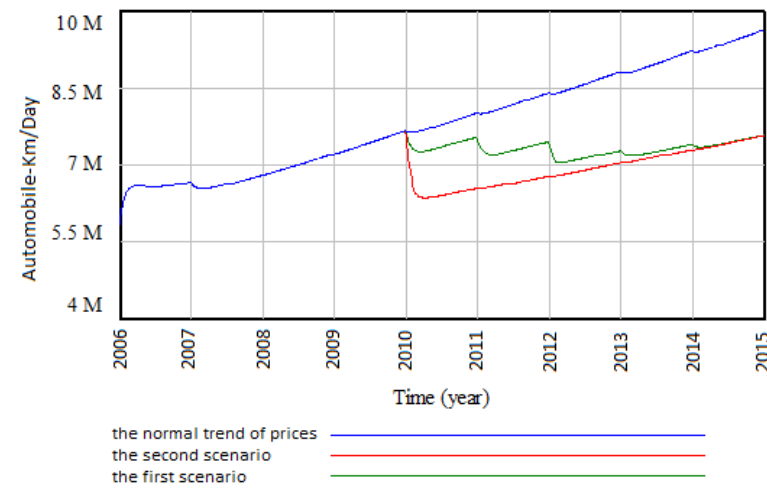

Fig. 9. Trend of "Traffic Volume" due to the scenarios compared to "the normal trend of prices"

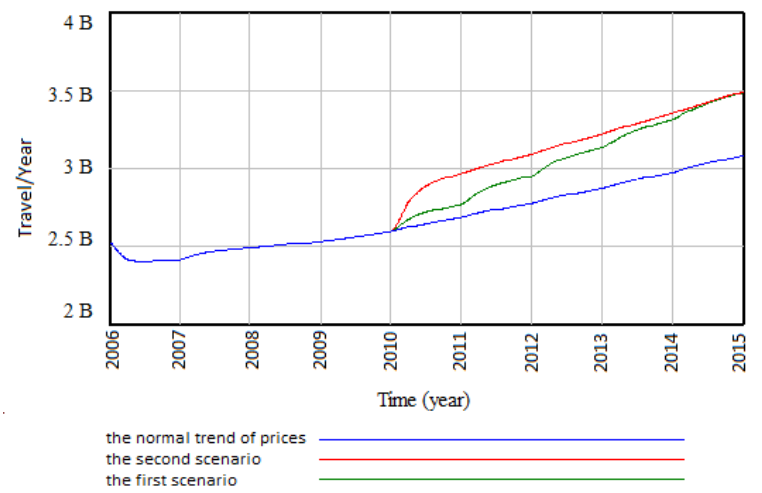

Fig. 10. Trend of "Travels By Public Transportation" due to the scenarios compared to "the normal trend of prices"

Why the amount of "Traffic Volume", despite the large decline in the beginning of the plan, still continues to increase, although this variable is controlled by some negative feedbacks? The reason is the increase in the number of the automobiles in the city, which is due to the growth of the population and increased automobile demand. If the "Travels per Day" or "Average Travel Distance", or both of them apart from the sudden drop, had an ascending trend, it was possible to have a fixed or at least lower "Traffic Volume" increase and this is only possible through having a descending "Driving Attractiveness" variable. Despite the increase in the "Driving Cost" variable will decrease this attractiveness, in long term the increase in "Society Welfare" prevents the "Driving Attractiveness" variable to considerably being decreased.

Of course, we should not ignore the low capacity of public transportation. Despite the increase in the "Public Transportation Capacity" we should say that if this increase had a greater amount of growth, the "Driving Attractiveness" variable could have a more decremental trend and after that, the numbers of daily travels, their distance and as a result the "Traffic Volume" had a lower growth rate. Although, according to the last diagram, we should say that the rate of traffic increase after the elimination of energy subsidies has been decreased a little compared with the time before the plan execution. Fig. 10 shows the situation of travels taken place with public transportation. Because in the second scenario, the shock in the prices is greater than the first one, as a result, more people in the beginning of this scenario were attracted to use public transportation and this will cause a sudden increase in the "Travels by Public Transportation". However, as the time passes by, this trend will be decreased and finds a more constant and moderate growth and therefore the next increases in the price of carriers, 
create no considerable changes. These changes are different in the first scenario. Although the increase in the number of public transportation users at the beginning of the plan is not as obvious as the second scenario, but as the time passes by and the amount of energy subsidies decreases more and more, this incremental trend is preserved and has a greater slope compared to the time before the plan execution and also the second scenario.

\section{References}

Ministry of Economic Affairs and Finance- Islamic Republic of Iran. (2010). An Introduction to the subsidies targeting plan, Publication of Working Group for Economic Reforms, 1, 4, http://www.mefa.gov.ir.

HooriJafari, H., \& FarahmandPur, B. (2008). Energy loans and its effect on the different parts of economics. Journal of Energy Economics Surveys, 2, 162-178.

Ministry of Economic Affairs and Finance- Islamic Republic of Iran. (2010). An Introduction to the subsidies targeting plan, Publication of Working Group for Economic Reforms, 1, 6, http://www.mefa.gov.ir.

Ministry of Economic Affairs and Finance- Islamic Republic of Iran. (2010). An Introduction to the subsidies targeting plan, Publication of Working Group for Economic Reforms, 1, 8, http://www.mefa.gov.ir.

The Secretariate of Working Group for Economic Reforms. (2008). The protector report of the total framework of the Economic Reform Plan (foundations, framework and the main topics of reforms). Report No. 1, 2, 27-30, http://www.mefa.gov.ir.

Power And Energy Planning Department- Ministry of Energy. (2010). Balance Sheet of Energy 2008, Tehran, Power and Energy Affairs, 20-21, http://pep.moe.org.ir.

Barabadi, M. (2009). Foreword. Journal of Traffic Engineering Issues, 38, 2.

Rahnama, M.R. (2008). The effects of dividing the distribution of petrol on changing the methods of city transportation in Mashhad. Journal of Social Sciences of Ferdowsi University of Mashhad, 5, 1-37.

Navabakhsh, M., \& Kaffashi, M. (2008). Social planning of transportation and its role in sustainable development (case study: city of Tehran), Bulletin of management and planning of city (2),18, 3132, Center For Strategic Researches, Iran, http://www.csr.ir.

Sterman, J.D. (2000). Business Dynamics, United States of America. Irwin McGraw-Hill.

Trinh T.A. (2003). System dynamic applied to study of the urban traffic congestion of Hanoi. Journal of Proceedings of the Eastern Asia Society for Transportation Studies, 4, 1693-1697.

Chen, C., Shao, L., Xu, L., \& Shang, J. (2009). A case study predicting environmental impacts of urban transport planning in China, International Journal of Environ Monit Assess, 157, 169-177.

Angerhofer, B.J., Angelides, M.C. (2000). System dynamics modeling in supply chain management: Research review. Proceedings of the 2000 Winter Simulation Conference, Orlando, FL, USA, 342351.

Salimian, Z., Kordbache, M., Sadeghi, M., Makarizadeh, V. (2010). Calculation of The Final Costs of Electricity Production in the Prices of Electricity and Other Energy Carriers also Plan Targeted Subsidies. 25th International Power System Conference, Iran, Tehran. 